\title{
Evaluation of Heart Rate Recovery in Patients with Diabetes Mellitus Type 2 and Elevated Urine Albumin/Creatinine Ratio After an Individualized Exercise Program
}

\author{
Urbina-Arronte LE ${ }^{1 *}$, Vergara-Juárez JJ ${ }^{2}$, Villegas-Narvaez AL ${ }^{1}$, García-Ulloa AC ${ }^{1}$ and Hernández-Jiménez S ${ }^{1}$ \\ ${ }^{1}$ Centro de Atención Integral del Paciente con Diabetes (CAIPaDi), Instituto Nacional de Ciencias Médicas y Nutrición Salvador Zubirán, Mexico \\ ${ }^{2}$ Departamento de Nefrología, Instituto Nacional de Ciencias Médicas y Nutrición Salvador Zubirán, Mexico
}

Submission: April 10, 2020; Published: August 27, 2020

*Corresponding author: Luz Elena Urbina Arronte, Centro de Atención Integral del Paciente con Diabetes (CAIPaDi) Instituto Nacional de Ciencias Médicas y Nutrición Salvador Zubirán, Vasco de Quiroga No. 15, Belisario Domínguez, Sección XVI, Tlalpan, 14080 Mexico

Abstract

Introduction: In a comprehensive approach, patients with diabetes who have evidence of microvascular damage should be considered to have abnormalities in various systems. This can modulate the expected response to the prescription of physical activity and exercise.

Objective: to evaluate the changes in autonomic nervous response in patients with T2DM and elevated albumin/creatinine ratio (ACR) after an individualized exercise program.

Methods: We analyzed data from patients with T2DM attending a comprehensive care program. We divide them in 2 groups (ACR $<30 \mathrm{mg} / \mathrm{g}$ and ACR $\geq 30 \mathrm{mg} / \mathrm{g}$ ); and compared metabolic, exercise and autonomic function parameters heart rate recovery (HRR) in the 6 minutes walking test (6MWT) and sudomotor function after 3 months with an exercise program.

Result: We included 988 patients, age $52 \pm 9.8$ years, $53 \%$ women, median time of diabetes diagnosis $1(0-5)$ years; $17.1 \%$ patients had ACR $\geq 30 \mathrm{mg} / \mathrm{g}$. Although the parameters improvement compared with baseline, at 3 months there were significant differences in the group with ACR $\geq 30 \mathrm{mg} / \mathrm{g}$ compared with normal renal function in A1c ( $6.3 \pm 0.8 \%$ vs $6.7 \pm 1 \%, \mathrm{p}<0.001)$, systolic blood pressure $(116.5 \pm 11 \mathrm{mmHg}$ vs 118 $\pm 13 \mathrm{mmHg}, \mathrm{p}<0.03)$, HRR at minute 1 (14 (9-20) min vs 17 (7-18) , p<0.01), HRR at minute 2 (21 (15-27) vs 19 (12-26), p=0.007) and the risk of autonomic cardiac neuropathy (33\% (25-40) vs $30 \%$ (23-38), $\mathrm{p}=0.01)$.

Conclusion: Patients with elevated urine albumin/creatinine ratio had a less HRR than patients with normal urine albumin creatinine ratio. It is important to consider kidney and autonomic function before exercise prescription in patients with T2DM.

Keywords: Albumin; Creatinine ratio; Cardiac autonomic neuropathy; Heart rate recovery; Type 2 diabetes Mellitus; Exercise

Abbreviations: ACR: Albumin Creatinine Ratio; T2DM: Type 2 Diabetes Mellitus; HRR: Heart Rate Recovery; 6MWT: 6 Minute Walking Test; AND: Autonomic Diabetic Neuropathy; T1DM: Type 1 Diabetes Mellitus; DN: Diabetic Nephropathy; EGFR: Glomerular Filtration Rate; HR: Heart Rate; ACEI: Angiotensin Converting Enzyme inhibitors; CAN: Cardiac Autonomic Neuropathy; ARB2: Angiotensin Receptor Blockers; BB: Beta Blockers; IPAQ: International Physical Activity Questionnaire; PA: Physical Activity; NE: No Exercise; RE: Resistance Exercise; AE: Aerobic Exercise; SAH: Systemic Arterial Hypertension; ADLS: Activities of Daily Living

\section{Introduction}

Type 2 diabetes (T2DM), causes macrovascular and microvascular complications. Autonomic diabetic neuropathy $(\mathrm{ADN})$ is a common and debilitating form of neuropathy. It can occur in a wide spectrum of manifestations that affect many systems of the human body, with different clinical implications [1]. An important microvascular complication that is often unrecognized by patients and physicians is cardiac autonomic neuropathy (CAN) [2,3]. The Subcommittee of Toronto Consensus

Panel on Diabetic Neuropathy defined CAN as the impairment of cardiovascular autonomic control in patients with diabetes after excluding other causes. The prevalence of CAN is variable in literature from 2 to $91 \%$ in type 1 diabetes (T1DM) and 25 to $75 \%$ in T2DM [4]. A study of Gutierrrez et al. in Mexican population reported a prevalence of $19.4 \%$ [5]. The clinical manifestations are orthostatism, resting tachycardia, exercise intolerance, silent myocardial infarction, intraoperative cardiovascular liability and sudden death [4-6]. The risk factors for CAN are poor glycemic 


\section{Current Research in Diabetes \& Obesity Journal}

control, time of diagnosis, older age, female, and positive smoking status [3,7]. There is an association between CAN and diabetic nephropathy (DN) where sympathetic overactivity causes renal and tubular dysfunction producing decline of the glomerular filtration rate (eGFR) [8]. Exercise benefits CAN and DN, improving glycolipid metabolism, weight control, insulin resistance, and blood pressure. Specifically, exercise training has proven to enhance parasympathetic activity and lower sympathetic activity [9]. These increase the regenerative capacity of cutaneous axons, slowing or preventing neuropathy progression [10], by increasing V02 max and Endothelial Growth Factor that entails tissue oxygenation [11]. Heart rate (HR) is regulated and determined predominantly by the autonomic nervous system function. The change in HR during exercise and recovery is controlled by the balance between sympathetic and parasympathetic activity $[6,7,12]$. An easy and non-invasive test to evaluate the cardiac autonomic function is the heart rate recovery (HRR) defined as the reduction of the heart rate at the end of exercise [12]. The aim of this study was to evaluate the HRR changes in patients with T2DM and elevated albumin/creatinine ratio (ACR) after 3 months of an individualized exercise program.

\section{Material Methods}

\section{Study population}

For this analysis we included consecutive patients from May 2014 to June 2019 who had finished the first three months of follow-up in the CAIPaDi model. The CAIPaDi program has been described elsewhere [13,14]. Briefly, the program addresses patients with type 2 diabetes, with $<5$ years of diagnosis, BMI $<45$ $\mathrm{kg} / \mathrm{m}^{2}$, non-smokers, and without disabling chronic complications. It includes interventions with 10 healthcare specialists, delivered in 7 hours. It seeks to achieve metabolic goals, and to identify and solve barriers that would make implementation difficult. The program consists of 4 visits delivered in 3 months and then annual evaluations.

\section{Procedures}

In each visit, 10 health care providers (nurses, diabetes educators, endocrinologist, ophthalmologist/optometrist, nutritionist, psychologist, dentist, psychiatrist, foot care specialist and exercise) attend every patient. Endocrinologists follow the Center's treatment guidelines and register hypoglycemic, lipid lowering, and antihypertensive drugs (including angiotensin converting enzyme inhibitors [ACEi], angiotensin receptor blockers [ARB2], beta blockers [BB]). In physical activity, therapists explain the difference between physical activity and exercise. In each visit, the barriers to do exercise were identified, and the patients and therapists in consensus proposed activities that could help them achieve adherence. Patients received an individualized exercise prescription, based on their cardiorespiratory fitness, articular pain, lifestyle, barriers, and considering the patient's preferences for a specific exercise. The American Diabetes Association recommendation for exercise in diabetes is to perform aerobic exercise 150 minutes per week and resistance exercise 15 repetitions of 1-3 series of each exercise [15]. We used de International Physical Activity Questionnaire (IPAQ) to assess the physical activity (PA), and the distance in the 6 minutes walking test (6MWT). We evaluated the HRR after 6MWT in a calibrated treadmill (Weslo Cadence R5.2 model 298164). Normal HRR was considered if the difference at $1^{\text {st }}$ minute was $\geq 12 \mathrm{bpm}$, and at the $2^{\text {nd }}$ minute was $\geq 22 \mathrm{bpm}$ [16]. Fasting concentrations of glucose, creatinine, lipids and HbA1c (Bio-Rad Variant II Turbo HbA1c Kit 2, with HPLC method) were assessed in each visit. Body composition was assessed by bioimpedance (body composition analyzer JAWON medical ioi353). The autonomous nervous system was assessed with electrical conductance of sweat gland function through Sudoscan ${ }^{\circledR}$ [17]. Albumin/creatinine ratio (ACR) (SYNCHRON CX system with colorimetric method) was used for screening diabetic nephropathy. The laboratory is certified by ISO 9001:2015 and the College of American Pathologist. We considered normal if ACR was $\geq 30 \mathrm{mg} / \mathrm{g}$. We separated patients in two groups, $\mathrm{ACR}<30 \mathrm{mg} / \mathrm{g}$ and $\geq 30 \mathrm{mg} / \mathrm{g}$.

\section{Statistical analysis}

Results data are reported as means $( \pm$ SD) or medians and interquartile ranges (25-75) if they followed or not a normal distribution, respectively. Normality was evaluated according to the Kolmogorov-Smirnov test. Percentages were used for discrete values. The analysis included t test for related samples and $t$ test for independent samples. McNemar and $\mathrm{x}^{2}$ tests were used for analyzing data from categorical variables. The analysis was adjusted for sex, age and drugs (ß-blockers and ACEi).

\section{Results}

We evaluated 988 consecutive patients from May 2014 to June 2019. There were 819 patients (82.9\%) in the ACR $<30 \mathrm{mg} / \mathrm{g}$ group: $445(54.3 \%)$ women, age $52.1 \pm 9.9$ years, $1(0-3)$ years of diagnosis, BMI $29.4 \pm 4.6 \mathrm{~kg} / \mathrm{cm}^{2}$, ACR $6.4(4.1-10.7) \mathrm{mg} / \mathrm{g}$. In the ACR $\geq 30 \mathrm{mg} / \mathrm{g}$ group were 169 patients (17.1\%), 79 (46.7\%) women, age $51.9 \pm 9.2$ years, $2(0-3)$ years of diagnosis, BMI $29.7 \pm 5.0 \mathrm{Kg} / \mathrm{cm}^{2}$, ACR 61 (39.2-131.65) mg/g. Table 1 shows the changes in metabolic parameters in both groups after the 3 months intervention. For visit 1 in the ACR $<30 \mathrm{mg} / \mathrm{g}$ group: $16.2 \%$ of patients had treatment indicated with ACEis, 15.2\% ARB2, and $2.4 \%$ BB. For visit $4,16.7 \%$ of patients had treatment indicated with ACEis, $15.1 \%$ ARB2, and 2.4\% BB. For visit 1 in the ACR $\geq 30 \mathrm{mg} / \mathrm{g}: 46.1 \%$ had indicated ACEIs, $19.2 \%$ ARB2, and $4.8 \% \mathrm{BB}$. In visit 4 the ACR $\geq 30 \mathrm{mg} / \mathrm{g}$ group had $43.7 \%$ were taking ACEis, $21 \%$ ARB2, and $4.8 \%$ BB. Table 2 shows the distribution of antihypertensive treatment of patients. The mean distance in 6 MWT of ACR $<30$ group was $409 \pm 93$ meters at basal and after 3 months the mean was $444 \pm 87$ meters ( $p<0.001$ ). In the ACR $\geq 30$ group the mean distance at basal evaluation was $399 \pm 93$ meters and at 3 months $431 \pm 94$ meters $(p<0.001)$. The first group achieved more distance, with no statically significant difference between groups at basal $(p=0.22)$, or after 3 months $(\mathrm{p}=0.11)$. Minute $1 \mathrm{HRR}$ at baseline was similar in both groups: the ACR group $<30$ obtained a median of $13(8-18) \mathrm{bpm}$ and the 


\section{Current Research in Diabetes \& Obesity Journal}

ACR group $\geq 30$ (6-17) bpm ( $\mathrm{p}=0.14)$. After 3 months of performed and individualized exercise program the median HRR was 14 (920) bpm and 17 (7-18) bpm, respectively ( $<<0.01)$. The median baseline minute 2 HRR was 19 (13-25) bpm in group ACR $<30$ and 18 (11-24) bpm in group ACR $\geq 30$ ( $p=0.07$ ). After 3 months of an individualized exercise program, group 1 obtained a median of 21 (15-27) bpm and the second group 19 (12-26) bpm ( $\mathrm{p}=0.007)$. Comparing visit 1 and visit 4, the percentage of patients in the group $<30 \mathrm{mg} / \mathrm{g}$ ACR that did not exercise (NE) decreased to $37 \%(\mathrm{p}<0.001)$ and resistance exercise $(\mathrm{RE})$ changed to $1 \%(\mathrm{p}$
$<0.001)$. Aerobic exercise (AE) increased $10 \%(\mathrm{p}=0.15)$, and $\mathrm{AE}$ + RE changed to $28 \%(\mathrm{p}<0.001)$. In the ACR $\geq 30 \mathrm{mg}$ group, the percentage of $\mathrm{NE}$ decreased to $36 \%(\mathrm{p}<0.001)$, increased the $\mathrm{AE}$ $16 \%(\mathrm{p}=0.18), \operatorname{RE} 1 \%(\mathrm{p}<0.001)$, and $\mathrm{AE}+\mathrm{RE}$ changed to $19 \%$ $(\mathrm{p}<0.001)$. Results of CAN from Sudoscan showed in ACR $<30$ group a decrease from $38(29-48) \%$ to $30(23-38) \%(\mathrm{p}<0.001)$ from basal to the fourth visit. In the ACR group $\geq 30$ the initial median was $45(35-54) \%$ and changed to $33(25-40) \%(\mathrm{p}<0.001)$ in the fourth visit. Results are shown in Table 1.

Table 1: Changes in metabolic and exercise parameters in both groups after 3 months of intervention.

\begin{tabular}{|c|c|c|c|c|c|c|}
\hline & \multicolumn{2}{|c|}{ ACR $<30$} & \multicolumn{2}{|c|}{ ACR $\geq 30$} & \multirow{2}{*}{$\mathbf{p}^{\mathrm{a}}$} & \multirow{2}{*}{$\mathbf{p}^{\mathbf{b}}$} \\
\hline & Basal & 3 months & Basal & 3 months & & \\
\hline $\mathrm{Hb} 1 \mathrm{Ac} \%$ & $8.1 \pm 2.2$ & $6.3 \pm 0.8^{*}$ & $9.8 \pm 2.7$ & $6.7 \pm 1 *$ & $<0.001$ & $<0.001$ \\
\hline SBPmmHg & $129 \pm 13.9$ & $116.5 \pm 11$ & $129 \pm 16.7$ & $118 \pm 13^{*}$ & $<0.001$ & 0.03 \\
\hline DBPmmHg & $76.6 \pm 7$ & $72.8 \pm 6^{*}$ & $79.1 \pm 7.9$ & $73.6 \pm 7 *$ & $<0.001$ & 0.13 \\
\hline Triglycerids mg/dl & $164(118-223)$ & $114(91-145)^{*}$ & $203(141-302)$ & $118(91-162)^{*}$ & $<0.001$ & 0.13 \\
\hline Total cholesterol mg/dl & $185 \pm 42.7$ & $150 \pm 29 *$ & $197 \pm 82$ & $150 \pm 29 *$ & $<0.001$ & 0.98 \\
\hline HDL Cholesterol mg/dl & $42.9 \pm 10$ & $45.4 \pm 10^{*}$ & $42.8 \pm 10$ & $45.4 \pm 10^{*}$ & 0.89 & 0.97 \\
\hline LDL Cholesterol mg/dl & $113 \pm 36$ & $88 \pm 24^{*}$ & $115 \pm 39$ & $87.3 \pm 25^{*}$ & 0.66 & 0.63 \\
\hline NoHDL Cholesterol mg/dl & $142 \pm 41$ & $105 \pm 27^{*}$ & $154 \pm 41$ & $105 \pm 26.7^{*}$ & $<0.001$ & 0.97 \\
\hline Moderate exercise (min/week) & $0(0-180)$ & $190(115-300) *$ & $0(0-160)$ & $175(80-280)$ & 0.45 & 0.14 \\
\hline NE n (\%) & 419 (51) & $112(14)^{*}$ & $92(54)$ & $30(18)^{*}$ & 0.44 & 0.22 \\
\hline AE n (\%) & 312 (38) & 390 (48) & $54(32)$ & $82(48)$ & 0.11 & 0.86 \\
\hline RE n (\%) & $16(2)$ & $12(1)^{*}$ & $2(1)$ & $3(2) *$ & 0.75 & 0.72 \\
\hline AE+RE n (\%) & $72(9)$ & $305(37) *$ & $21(13)$ & $54(32) *$ & 0.14 & 0.25 \\
\hline Distance m & $409 \pm 93$ & $444 \pm 87^{*}$ & $399 \pm 93$ & $431 \pm 94^{*}$ & 0.22 & 0.11 \\
\hline HRR min 1 & $13(8-18)$ & $14(9-20) *$ & $13(6-17)$ & $17(7-18)$ & 0.14 & 0.01 \\
\hline HRR $\min 2$ & $19(13-25)$ & $21(15-27) *$ & $18(11-24)$ & $19(12-26)$ & 0.07 & 0.007 \\
\hline Risk CAN & $38(29-48)$ & $30(23-38) *$ & $45(35-54)$ & $33(25-40) *$ & $<0.001$ & 0.01 \\
\hline
\end{tabular}

HbA1c: Glycated Hemoglobin; SBP: Systolic Blood Pressure; DBP: Diastolic Blood Pressure; NE: No Exercise; AE: Aerobic Exercise; RE: Resistance Exercise; HRR: Heart Rate Recovery; CAN: Cardiac Autonomic Neuropathy. ${ }^{*} p<0.001$ basal and 3 months intragroup, $p^{a}$ basal between groups, $p^{\mathrm{b}} 3$ months between groups

Table 2: Distribution of antihypertensive treatment of patients.

\begin{tabular}{|c|c|c|c|}
\hline & $\mathrm{ACR}<30$ & $\mathrm{ACR} \geq 30$ & \multirow{2}{*}{$\mathbf{p}$} \\
\hline & n (\%) & n (\%) & \\
\hline ACEIs previous & $62(7.6)$ & $14(8.4)$ & 0.75 \\
\hline ACEIs indicated V1 & $133(16.2)$ & $77(46.1)$ & $<0.001$ \\
\hline ACEIs indicated V4 (3 months) & $137(16.7)$ & $73(43.7)$ & $<0.001$ \\
\hline BB previous & $20(2.4)$ & $8(4.8)$ & 0.12 \\
\hline BB indicated V1 & $20(2.4)$ & $8(4.8)$ & 0.12 \\
\hline BB indicated V4 (3 months) & $20(2.4)$ & $8(4.8)$ & 0.12 \\
\hline ARB 2 previous & $103(12.5)$ & $25(15)$ & 0.37 \\
\hline ARB 2 indicated V1 & $125(15.2)$ & $32(19.2)$ & 0.24 \\
\hline ARB 2 indicated V4 (3 months) & $124(15.1)$ & $35(21.0)$ & 0.1 \\
\hline
\end{tabular}

ACEI: Angiotensin Converting Enzyme Inhibitors; BB: Beta Blockers; ARB2: Angiotensin Receptor Blockers; V1: Visit 1; V4: Visit 4 


\section{Current Research in Diabetes \& Obesity Journal}

\section{Discussion}

In this paper we evaluated the HRR changes in patients with T2DM and elevated albumin/creatinine ratio (ACR) after 3 months of an individualized exercise program. Although both groups are patients with recent diagnosis of diabetes, the ACR $\geq 30$ $\mathrm{mg} / \mathrm{g}$ has 1 more year of diagnosis. Radica et al showed in their study that after 10 years of diagnosis, patients with T2DM can present damage in kidney). Aring et al [18] mentioned that CAN may appear 1 or 2 years after the diagnosis of diabetes but usually develops in patients with 20 years or more of diagnosis [19]. This study demonstrates that many chronic complications can start long time even before the diagnosis of diabetes is made. As described by Spijkerman et al in their article that type 2 diabetes is characterized by an asymptomatic phase that is estimated to last $4-7$ years where $30-50 \%$ of patients have no diagnosis of diabetes. In their results, $26.7 \%$ of patients with a new diagnosis of diabetes had microalbuminuria, similar to our results [20]. In our study, we included the 2 main types of antihypertensive drugs that have a renoprotective impact for the progression of diabetic nephropathy (ACEIs and ARB2) [21]. In our Center, these drugs were indicated with a double function for the control of hypertension and albuminuria, being $43 \%$ of the population with ACR $\geq 30 \mathrm{mg} / \mathrm{g}$ and systemic arterial hypertension SAH, of which $61 \%$ had ACEIs, 23\% ARB2, 6.8\% BB, and 9.2\% other antihypertensive drugs. Obesity is a strong risk factor to develop kidney disease [22]. And cardiovascular complications [23]. Our patients are overweight and obese in a higher proportion in patients with ACR $\geq 30 \mathrm{mg} / \mathrm{g}$. The progression of the damage can be prevented through strict glycemic, lipid and weight control [8]. Cole C. et al, [24] showed in their study that abnormal values of HRR are a strong predictor of mortality [24]. And Sing JP et al mentioned that risk of cardiovascular disease in patients with T2DM with albuminuria is two or three times higher than patients without albuminuria [25]. Adequate exercise has shown many benefits improving the cardiac autonomic function and the microvasculature. By this means, exercise prevents diabetes complications [26]. In our study both groups decreased the risk of CAN and improved metabolic and exercise parameters after an individualized exercise program for 3 months. Exercise intolerance directly affects the limitation of activities of daily living (ADLs), reducing the quality of life, [27]. An abnormal HRR reflects exercise intolerance. In the group of ACR $\geq 30 \mathrm{mg} / \mathrm{g}$ we found that this phenomenon is more evident since the HRR was lower at the end of the study compared to the group of ACR $<30 \mathrm{mg} / \mathrm{g}$. By this means, when patients improve HRR, exercise tolerance and their ability to perform activities of daily living increase without difficulty. Other authors didn't find statically difference in percentages between groups (with/without microalbuminuria), abnormal HRR in the first minute was present in $12.9 \%$ patients with microalbuminuria and abnormal HRR $7.1 \%$ patients without microalbuminuria. In the second minute abnormal HHR was present in $9.7 \%$ patients with microalbuminuria and $7.1 \%$ patients without microalbuminuria without statistically significant difference between the two groups [2]. Therefore, autonomic nervous system test may offer a useful tool to identify patients with potentially poor exercise performance and to prevent hazard when they are introduced to exercise training programs [28]. This can be assessed with the 6MWT, which is an easy and not expensive test to those patients with recent DMT2 diagnostic. It is important to evaluate and establish aspecific exercise program, finding strategies to overcome barriers and improve exercise adherence and cardiorespiratory fitness. We must consider if patients with T2DM have kidney damage to prescribe a specific exercise program. This strategy helps improve the activity of the autonomic nervous system increasing their exercise capacity and improve performance in their ADLs.

\section{Conclusion}

Patients with urine ACR elevated had a worst HRR, than patients with normal ACR. Both groups improve their metabolic and exercise parameters after an individualized exercise program especially in HRR what it entails to have quality of life and prevention of more diabetes complications.

\section{Acknowledgement}

Group of Study CAIPaDi: María Teresa Alcántara-Garcés, Denise Arcila-Martínez, Rodrigo Arizmendi-Rodríguez, Michelle Díaz-Pineda, Oswaldo Briseño-González, Humberto Del ValleRamírez, Arturo Flores García, Fernanda Garnica-Carrillo, Eduardo González-Flores, Mariana Granados-Arcos, Héctor Infanzón-Talango, María Victoria Landa-Anell, Claudia LechugaFonseca, Arely López-Reyes, Marco Antonio Melgarejo-Hernández, Liliana Pérez-Peralta, Sofía Ríos-Villavicencio, David Rivera de la Parra, Francis Rojas-Torres, Sandra Sainos-Muñoz, Alejandra Sierra-Esquivel, Erendi Tinoco-Ventura, María Luisa VelascoPérez, Héctor Velázquez-Jurado, Verónica Zurita-Cortés, Carlos A. Aguilar-Salinas, Francisco J Gómez-Pérez, David KershenobichStalnikowitz.

\section{Conflict of Interest}

The authors declare no potential conflicts of interest with respect to the research, authorship and/or publication of this article.

\section{Funding}

The CAIPaDi program has received grants from Astra Zeneca, Fundación Conde de Valenciana, Novartis, Consejo Nacional de Ciencia y Tecnología ("Proyectos de Desarrollo Científico para Atender Problemas Nacionales 2013 project 214718), Nutrición Médica y Tecnología, NovoNordisk, Boehringer Ingelheim, Dirección General de Calidad y Educación en Salud, Eli Lilly, Merck Serono, MSD, Silanes, Chinoin and Carlos Slim Health Institute. There are no other potential conflicts of interest relevant to this 


\section{Current Research in Diabetes \& Obesity Journal}

article.

\section{References}

1. Elshazly A, Hanna H, Ali A (2018) Effect of exercise training on heart rate recovery in patients post anterior myocardial infarction. The Egyptian Heart Journal 70(4): 283-285.

2. Pourmoghaddas A, Moghaddasian A, Mohammad G, Nezarat N, Mehrabi A (2013) Heart rate recovery in exercise test in diabetic patients with and without microalbuminuria. ARYA atheroscle 9(3): 167-171.

3. Pan Q, Li Q Deng W, Li Ma, Yao H, et al. (2019) Prevalence and Diagnosis of Diabetic Cardiovascular Autonomic Neuropathy in Beijing, China: A Retrospective Multicenter Clinical Study. Front Neurosci 13: 1144.

4. Agashe S, Petak S (2018) Cardiac Autonomic Neuropathy in Diabetes Mellitus. Methodist debakey cardiovasc Journal 14(4): 251-256.

5. Gutiérrez AJ, Montes ML, Jiménez JH (2012) Prevalencia de neuropatía autonómica cardiovascular en pacientes con diabetes mellitus tipo 2 y estandarización en población mexicana por medio de la variabilidad de la frecuencia cardiaca. Revista mexicana de Medicina Física y Rehabilitación 24: 45-55.

6. Verrotti A, Prezioso G, Scattoni R, Chiarelli F (2018) Autonomic Neuropathy in diabetes. Frontiers in endocrinology 5: 205.

7. Röhling M, Strom A, Bönhof GJ, Roden M, Ziegler D (2017) Cardiorespiratory Fitness and Cardiac Autonomic Function in Diabetes. Current Diabetes Reports 17(12): 125.

8. Tahrani AA, Dubb K, Raymond NT, Begum S, Hamed S, et al. (2014) Cardiac autonomic neuropathy predicts renal function decline in patients with type 2 diabetes: a cohort study. Diabetologia 57(6): 1249-1256.

9. Liu Y, Liu S, Zheng F, Cai Y, Ling X K, et al. (2015) Cardiovascular autonomic neuropathy in patients with type 2 diabetes. Journal of Diabetes Investigation 7(4): 615-621.

10. Villafaina S, Collado D, Fuentes JP, Merellano E, Gusi N (2017) Physical Exercise Improves Heart Rate Variability in Patients with Type 2 Diabetes: A Systematic Review. Current Diabetes Reports 17(11): 110.

11. Radak Z, Zhao Z, Koltai E, Ohno H, Atalay M (2013) Oxygen Consumption and Usage During Physical Exercise: The Balance Between Oxidative Stress and ROS-Dependent Adaptive Signaling. Antioxidants \& Redox Signalin 18(10): 1208-1246.

12. Qiu S, Cai X, Sun Z, Li L, Martina Z, et al. (2017) Heart Rate Recovery and Risk of Cardiovascular Events and All-Cause Mortality: A Meta-Analysis of Prospective Cohort Studies. J Am Heart Assoc 6(5): e005505.

13. Hernández S, Garcia AC, Mehta R, Aguilar CA, Kershenobich D (2014) Innovative models for the empowerment of patients with type 2 diabetes: the CAIPaDi program. Recent Pat Endocr Metab Immune Drug Discov 8(3): 202-209.

14. Hernández S, Garcia AC, Bello OY, Aguilar CA, Kershenobich D (2019)
Long-term effectiveness of a type 2 diabetes comprehensive care program. The CAIPaDi model. Diabetes Res Clin Pract 151: 128-137.

15. Colberg SR, Sigal R, Yardley JE, Daviv D, Kristin C, et al. (2016) Physical Activity/Exercise and Diabetes: A Position Statement of the American Diabetes Association. Diabetes Care 39(11): 2065-2079.

16. Lipinski MJ, Vetrovec GW, Froelicher VF (2004) Importance of the first two minutes of heart rate recovery after exercise treadmill testing in predicting mortality and the presence of coronary artery disease in men. The American Journal of Cardiology 93(4): 445-449.

17. Casellini CM, Parson HK, Richardson MS, Nevoret ML, Vinik AI (2013) Sudoscan, a Noninvasive Tool for Detecting Diabetic Small Fiber Neuropathy and Autonomic Dysfunction. Diabetes Technology \& Therapeutics 15(11): 948-953.

18. Alicic RZ, Rooney MT, Tuttle KR (2017) Diabetic Kidney Disease Clinical Journal of the American Society of Nephrology 12(12): 20322045.

19. Aring AM, Jones DE, Falko JM (2005) Evaluation and prevention of diabetic neuropathy. Am Fam Physician 71(11): 2123-2128.

20. Spijkerman A, Dekker J, Nijpels G, Marcel G, Piet J K, et al. (2003) Microvascular complications at time of diagnosis of type 2 diabetes are similar among diabetic patients detected by targeted screening and patients newly diagnosed in general practice. Diabetes Care 26(9): 2604-2608.

21. Dounousi E, Duni A, Leivaditis K (2015) Improvements in the Management of Diabetic Nephropathy. The Review of Diabetes Studies 12(1-2): 119-133.

22. Kovesdy C, Furth S, Zoccali C (2017) Obesity and Kidney Disease: Hidden Consequences of the Epidemic J Nephrol 27(2): 85-92.

23. Sowers JR (2003) Obesity as cardiovascular risk factor. American Journal of Medicine 115(8A): 37S-41S.

24. Cole C, Blackstone E, Pashkow F, Snader C, Lauer M (1999) Heart-rate recovery immediately after exercise as a predictor of mortality. The New England Journal of Medicine 341: 1351-1357.

25. Singh JP, Larson MG, O’Donnell CJ, Wilson P F, Tsuji H, et al. (2000) Association of hyperglycemia with reduced heart rate variability (The Framingham Heart Study). Am J Cardiol 86(3): 309-312.

26. Sydo N, Sydo T, Gonzalez K, Nasir H, Farooq S, et al. (2018) Prognostic Performance of Heart Rate Recovery on an Exercise Test in a Primary Prevention Population. Journal of the American Heart Assoc 7(7): e008143.

27. Belfer M, Reardon J (2009) Improving Exercise Tolerance and Quality of Life in Patients with Chronic Obstructive Pulmonary Disease. J Am Osteopath Assoc 109(5): 268-278.

28. Besnier F, Labrunée M, Pathak A, Anne P LT, Gales C, et al. (2017) Exercise training-induced modification in autonomic nervous system: An update for cardiac patients. Annals of Physical and Rehabilitation 


\begin{tabular}{|l|}
\hline \multicolumn{1}{|c|}{ Your next submission with Juniper Publishers } \\
will reach you the below assets \\
- Quality Editorial service \\
- Swift Peer Review \\
- Reprints availability \\
- E-prints Service \\
- Manuscript Podcast for convenient understanding \\
- Global attainment for your research \\
- Manuscript accessibility in different formats \\
( Pdf, E-pub, Full Text, Audio) \\
- Unceasing customer service \\
Track the below URL for one-step submission \\
https://juniperpublishers.com/online-submission.php \\
\hline
\end{tabular}

